\title{
Visões de Vargas: uma comparação entre as memórias de três intelectuais
}

Visions of Vargas: a comparison between the memories of three intellectuals

Visiones de Vargas: Una comparación entre las memorias de tres intelectuales

Eduardo Gusmão de Quadros

\section{Resumo}

A literatura autobiográfica é uma rica fonte para o conhecimento do passado, apesar das armadilhas que apresenta. Este artigo aborda três obras desse gênero, publicadas por intelectuais militantes: o católico Alceu Amoroso Lima, o comunista Nelson Werneck Sodré e o liberal de direita Miguel Reale. O eixo da investigação é a interpretação que estas fizeram da Revolução de 1930 e do Presidente Vargas.

Palavras-chave: Intelectuais. Autobiografia. Revolução de Trinta. Getúlio Vargas.
Os relatos autobiográficos nem sempre foram muito valorizados como fonte histórica. Havia aquela busca de saber o que aconteceu, dentro de uma perspectiva objetiva, e o mais interessante do relato memorialístico é justamente o julgamento sobre o acontecido. É verdade que os autores costumam valorizar a objetividade de seus relatos, invocam provas e documentos como comprovantes do que escrevem. Porém, se os relatos ficassem apenas na descrição, por que seriam necessários tantos registros pessoais?

George Duby (1990, p. 45) fala da desconfiança que aprendera a ter com esse tipo de fonte, individualista e subjetiva. Amplia,

Doutor em História pela Universidade de Brasília. Professor da Universidade Estadual de Goiás e da Pontifícia Universidade Católica de Goiás.

Recebido em 01/09/2012 - Aprovado em 12/01/2013

http://dx.doi.org/10.5335/hdtv.13n.2.3720 
até, para a desconfiança com as narrativas em geral, sempre relatos fragmentários que dão a impressão de totalidade e de veracidade. Os paradigmas mudaram, e são os aspectos subjetivos - totalizantes e verídicos, em certo sentido - que, hoje, busca-se captar nos processos históricos. Daí a relevância que passou a ser dada aos estudos biográficos e da memória, feitos com maestria pelo próprio Duby (1995) em sua maturidade.

Não devemos, contudo, exagerar nas oposições. Seria uma armadilha epistemológica optar pelo subjetivo ou pelo objetivo, pelo individual ou pelo coletivo, pelo particular ou pelo total. De maneira isolada, qualquer um desses termos seria uma mera abstração, espécie de entidade metafísica. A lembrança está exatamente no espaço intermediário, em movimento dinâmico por meio desses polos.

Pode-se compreender isso melhor a partir da categoria de testemunho. Ela confere ao relato um grau de autenticidade, de confiabilidade, ao mesmo tempo em que exige do leitor/ouvinte atitude de averiguação. Paul Ricoeur caracteriza bem, em seis pontos focais, a importância e a dificuldade de trabalhar com essa forma de relato. A literatura testemunhal, assim, representa:

1 - A afirmação de uma realidade factual, acerca do acontecido, acoplada com a declaração da experiência de seu autor - seu "discurso" - indicando uma forma possível de compreender o passado;

2 - A centralidade da autodesignação no registro, afirmando a capacidade do sujeito de relatar, resumida pela fórmula: "eu ali estava";
3 - A inscrição de uma postura dialogal em que a autodesignação conjuga-se com o ato de apresentar-se a outrem pedindo: "confie em mim".

4 - O pedido de crédito que pressupõe uma desconfiança por parte do ouvinte/leitor. Essa atitude de suspeita demanda do autor a argumentação retórica típica do espaço público;

5 - A dimensão ética do relato demonstrada pelo "encontro" - de natureza fictícia, claro - pois há uma promessa do enunciador de ser autêntico, de expor sua individualidade, sendo plenamente verdadeiro;

6 - A natureza social do testemunhar, que inclusive institui os agentes sociais, certos hábitos de memória, regras narrativas, atitudes linguísticas, enfim, uma reciprocidade fiduciária entre as vidas vinculadas (RICOEUR, 2000, p. 204-208).

Pode-se perceber que os três primeiros tópicos apontam mais para o si mesmo, para o "auto" da autobiografia, enquanto os três últimos indicam a importância social do ato de contar a vida. É com essa visão hermenêutica que estudaremos as três obras selecionadas, buscando compreender melhor o período da Revolução de 1930 e do Estado Novo. São livros autobiográficos, de autores com opções distintas em suas carreiras, apesar de todos serem intelectuais de renome nacional desde aquela época. As obras selecionadas são as Memórias improvisadas, de Alceu Amoroso Lima (1972), um pensador católico envolvido nas questões sociais e políticas e as Memórias de um soldado, redigidas pelo intelectual comunista Nelson Werneck 
Sodré (1967). A terceira, as Memórias escritas por Miguel Reale (1987), professor de direito e politicamente de direita. Com isso, veremos olhares distintos acerca do personagem Getúlio Vargas.

\section{Armadilhas intelectuais}

O termo intelectuais utilizado para unificar os três autores não é tão claro quanto parece. A figura do intelectual é relativamente recente, podendo ser datada dos finais do século XIX. Verdade que Jacques Le Goff aplicou esse termo a um livro sobre o período medieval (LE GOFF, 1988). Contudo, seu estudo é voltado para os professores universitários e teólogos, não para os escritores propriamente ditos.

O conceito, portanto, tem suas ambiguidades. Jean-François Sirinelli tentou defini-lo, afirmando sua importância para a história política, mas conclui que os contornos do grupo são demasiados vagos e imprecisos (1996, p. 233). De qualquer modo, existe certa sociabilidade, certos ambientes e gostos comuns que identificam esse grupo. Michel Winock (2000) teceu um amplo mapeamento dos intelectuais franceses, suas revistas, produções e militâncias, mas nas quase mil páginas de sua obra evita dar uma definição cabal. O que fica evidente é que os intelectuais conjugam seus dotes artísticos no caso específico, a escrita literária - com o engajamento em problemas sociais e políticos de seu tempo. Outra conclusão a que se pode chegar com esta ampla pesquisa é que os intelectuais estão sempre em construção, vivendo com um grau de incerteza e instabilidade, mesmo que mantenham liderança nos debates públicos e sejam formadores de opinião.

Daniel Pecault trabalhou com essa perspectiva a respeito da história brasileira. Ser intelectual, afirma logo de início, "é ser engajado e atuar em causas que não lhe pertencem" (1990, p. 5). No entanto, esse desinteresse pessoal que os leva a agir sobre o que "não lhes pertencem" torna-se bastante relativo, pois como demonstrou o próprio autor, a relação entre a produção intelectual e o estado brasileiro sempre foi íntima. Um "lucro" pessoal sempre aparece nessas relações com a governabilidade. Sérgio Miceli (1979), certamente o maior estudioso brasileiro sobre a temática, demonstra igualmente essa situação de dependência ao dissecar as estratégias daqueles que buscaram viver "de ideias" nas décadas de 1920 e 1930. Os pesquisadores trazem em comum o referencial interpretativo das teorias de Pierre Bourdieu.

O famoso sociólogo francês voltou várias vezes à temática em sua extensa obra (BOURDIEU, 2004). O pressuposto de suas análises é exatamente este: viver pelos ideais, produzindo e divulgando ideias, possui uma dimensão material forte, espaços constituídos socialmente, especialmente nos últimos dois séculos, para a consagração desses "criadores de cultura". Portanto, suas obras só podem ser plenamente compreendidas dentro da produção de bens simbólicos que gestam e perpetuam o próprio campo intelectual.

Apesar da sofisticação das teorias bourdieusianas, a nosso ver, ele pouco avançou em termos de método em relação ao que já propunha Antonio Gramsci na primeira metade do século passado: 
O erro metodológico mais difundido, ao que me parece, consiste em se ter buscado esse critério de distinção no que é intrínseco às atividades intelectuais, ao invés de buscá-lo no conjunto do sistema de relações no qual essas atividades (e, portanto, os grupos que as personificam) se encontram no conjunto geral das relações sociais (GRAMSCI, s/d, p. 10).

Esse princípio nos leva a ler com certa desconfiança as narrativas autobiográficas dos intelectuais. Afinal, elas são centradas na consciência, em dados lembrados e reconstituídos em forma de uma narrativa coerente, e sabemos que a vida não ocorre bem assim. Por outro lado, os autores que se propuseram a redigir memórias buscam apresentar um lado oculto de suas carreiras, aspectos subjetivos que, aos olhos dos autores, lhes pareceram relevantes para registro. Tal aspecto interpretativo dos fatos públicos, como afirma Ângela de Castro Gomes, é o que torna "a escrita de si" tão relevante como fonte histórica (2004, p. 15).

Os escritores assumidos, neste artigo, como fonte construíram visões interpretativas de quem fora Vargas e comentaram como conseguira permanecer por mais uma década no cargo supremo da Nação. Faz-se relevante tratar da reconstrução de si, da narração de suas vidas, em consonância com os fatos e personagens que vivenciaram, sem que um nível sobreponha-se exatamente ao outro. Nosso olhar externo, de historiador que conhece outras fontes documentais, sobrepõe outra dimensão de análise ao localizar suas atividades intelectuais dentro de uma rede maior, na sociabilidade que demarca as lembranças que expuseram. Essas condições do perceber, do pensar e do escrever são tão fundamentais quanto as impressões que deixaram registradas e, agora, podem ser lidas.

\section{A síntese de Alceu}

Comecemos pelo mais velho dos três. Alceu Amoroso Lima nasceu em 1893 no Rio de Janeiro, formou-se em direito, foi professor e crítico literário, tornando-se famoso por sua militância católica. Esse diferencial religioso é destacado em suas Memórias improvisadas, que retoma diversas vezes o tema de sua "conversão", ocorrida em 1928.

Além desse diferencial, a obra distingue-se das outras por não ser exatamente uma autobiografia, mas uma série de entrevistas concedidas ao jornalista Medeiros Lima por cerca de oito meses. O título pode remeter ao aspecto de memória provocada, de relato biográfico construído a partir das perguntas, mas, curiosamente, encontramos uma obra com título idêntico, feita por outro converso ao catolicismo: Paul Claudel (1954). Alceu, é bom lembrar, escreveu um pequeno ensaio em que demonstra sua admiração pelo poeta e dramaturgo francês e, talvez, tenha sugerido esse título idêntico ${ }^{1}$.

Quando ocorreu a Revolução de 1930, Alceu já coordenava o Centro D. Vital, que reunia intelectuais e militantes católicos. Esse centro tem sido considerado um bastião do pensamento político conservador e a revista que editava, denominada $A$ ordem, expressava isso em seu próprio título (DIAS, 1996). A postura predominante era a de lutar pela presença dos ideais católicos na política, na sociedade e na cultura. Nada de conformismo, destarte, mas um trabalho 
árduo vinha sendo feito em torno do projeto de neo-cristandade ${ }^{2}$ em vigor. O movimento político de Getúlio Vargas não seria um momento propício para executá-lo?

Alceu lembra-se do dia 24 de outubro de 1930 no qual estava indo à delegacia de polícia para interceder por uns amigos. Sabia do movimento revolucionário previamente, pois fora avisado pelo Cardeal D. Leme, arcebispo do Rio de Janeiro. Esse cardeal foi o negociador do afastamento de Washington Luis, buscando garantir tanto os direitos do presidente derrubado quanto o não derramamento de sangue ${ }^{3}$. Ao sair da delegacia, já havia um carnaval nas ruas, diz ele (LIMA, 1972, p. 214). A impressão transmitida é que a Revolução de 1930 fora desejada pela população e pela igreja, conseguindo a vitória sem cometer muita violência. Entretanto, alguns parágrafos depois, o autor afirma categórico: "fui contra a revolução de 1930 [...]; fiz questão de dar de público o meu testemunho de desaprovação a um movimento que me parecia contrário aos interesses nacionais" (1972, p. 417). Como entender tal divergência?

Poderíamos invocar as variações constantes da memória, ou o poder de reconstrução da consciência que costuma remodelar e apaziguar os conflitos. Entretanto, cremos que a ambiguidade apontada de algum modo reflete a posição oficial do catolicismo. Havia setores que apoiavam Vargas desde a campanha presidencial, como D. João Becker, o arcebispo de Porto Alegre. Por outro lado, D. Leme, considerado o líder da igreja brasileira e interlocutor privilegiado junto ao governo revolucionário, faz questão de resguardar a independência da instituição eclesiástica.
Uma comprovação dessa posição é a criação da Liga Eleitoral Católica. Essa organização deveria orientar o voto dos católicos para os candidatos que seguissem os princípios pregados pelo catolicismo. Alceu foi o secretário geral da Liga e em suas memórias ressalta que naquele momento "a igreja assumia um papel intervencionista na política, embora no plano suprapartidário" (1972, p. 309). A nosso ver, essa postura de se resguardar, de uma posição fora dos conflitos, é típica de uma instituição que se considera sagrada. É como se ela observasse a história de forma independente, ou do ponto de vista de Deus.

A postura ambígua permanece em outros trechos. Avaliando o Estado Novo, por exemplo, Amoroso Lima começa criticando:

Tendo sido contrário à revolução de 1930, não aceitei também o golpe de 1937. Não podia concordar com a transformação do estado nos termos em que era feita. Tratava-se de um retrocesso, já que substituíam as instituições livres por um sistema baseado no autoritarismo e no centralismo político, contrário ao espírito federativo e às liberdades públicas. (1972, p. 218)

Contudo, algumas linhas abaixo ele postula que: "O Estado Novo errou politicamente, mas acertou socialmente" (1972, p. 219). Essa reavaliação positiva prossegue ao descrever a personalidade do presidente da República, com quem teve diversos encontros:

Foi uma pessoa afável, risonha, simpática, com grande habilidade no trato dos homens e sem nenhum sinal de arrogância dos caudilhos e ditadores modernos. [...] Foi um civil, sereno, singular, amável, perspicaz, que soube admiravelmente compreender a psicologia do povo brasileiro e pegava as ocasiões pelo cabelo (1972, p. 219). 
O mais característico da narrativa de Alceu está nessa busca de sínteses impossíveis, dessas avaliações nas quais ele tenta identificar o bem e o mal colocando-se, para ser correto, além destes. Ele chega a denominar tal capacidade de análise de "fatologia", invocando um princípio, para nós, da filosofia positivista, mas que ele afirma pertencer à escolástica medieval: "Diante do fato não há argumento" (1972, p. 276). Então, a objetividade de suas descrições tornaria-se inquestionável, exatamente porque ele teria esse afastamento crítico necessário à análise dos bons intelectuais. Com religião ou não, reforça-se um mito.

\section{A disciplina de Sodré}

Nelson Werneck Sodré ficara conhecido pela aplicação das teorias marxistas à história e à literatura brasileiras ${ }^{4}$. Contudo, das páginas de seu livro de memórias emerge um retrato bem diferente do dogmático, autoritário e pouco criativo intelectual comunista pintado por José Carlos Reis (1999, p. 145-172). Não há, aliás, corte radical entre o pesquisador, o militar e o comunista na sua narrativa autobiográfica, nem existem grandes rupturas a exemplo da "conversão" enfatizada por Alceu.

As Memórias de um soldado seguem uma cronologia rígida, desde o nascimento do intelectual militar, em 1911, no Rio de Janeiro. Existe em sua escrita um cuidado especial em não ser anacrônico e projetar opiniões tardias em um período anterior. Com essa intenção enunciada, ele confere certo ar de cientificidade quando confessa que não costuma rasgar "papéis, cartas, documentos", conservando-os "cuidadosamente guardados e separados, conforme a procedência e o assunto". Ele reconstitui sua vida, portanto, mesclando as lembranças com esses "papéis velhos", e busca evitar "a deformação que a distância no tempo lhes confere" (1967, p. 245).

Outro exemplo do rigor da sua escrita autobiográfica advém das exigências morais que expressa. Confessa, com certa discrição é certo, algumas falhas que cometeu como colar na escola $(1967$, p. 67), ou a punição excessiva que aplicava aos negros e nordestinos no início de sua carreira militar (1967, p. 112). Esse grau de exigência alto lhe parece característico dos jovens oficiais que, como ele, queriam praticamente "consertar o exército" (1967, p. 104), mas nota-se na narrativa que o impulso não morrera com sua juventude.

Um terceiro aspecto a ser destacado são as "lições" que extrai de alguns acontecimentos. O texto aproxima-se de uma crônica em seu cuidado com a cronologia e com a objetividade, mas uma vez ou outra o professor Nelson, da Escola do Estado Maior, emerge fornecendo princípios gerais, como se quisesse ensinar seus leitores como agir. No caso das punições, por exemplo, ele conclui que:

O equilíbrio de um julgamento vem com a experiência, nem sempre diretamente ligada ao tempo, mas à capacidade em aprender as lições da vida mais difíceis que as dos livros. É um erro supor que os subordinados apreciam a cega e indiscriminada benevolência, que transforma a tolerância em licença; eles são justos na avaliação da autoridade, quase sempre: o julgamento dos que dependem de nós é melhor do que o dos pares... (1967, p. 117). 
Em 1930, Nelson era ainda estudante interno do colégio militar no Rio de Janeiro. Essas condições não o impedem, entretanto, de exercer sua curiosidade em observar os primeiros passos do novo regime. Um pouco antes de outubro, comenta a revolta dos "sentimentos populares" com o resultado forjado das eleições presidenciais. Há opiniões diversas e Getúlio Vargas "fez as declarações ambíguas em que era mestre, mantendo as pontes com o Catete" (1967, p. 47). Como se vê, ele aponta para certa base popular do movimento outubrista, sentido na capital federal, além de considerar o caráter negociador de Vargas como algo negativo. Pelos dados que coloca em sua narrativa, essa não era somente sua opinião, mas pode ser estendida a setores do exército que acabaram por entregar o poder e empossar Getúlio (1967, p. 51).

As ambiguidades getulistas são retomadas quando declara seu apoio ao movimento constitucionalista de 1932:

Confesso que minhas simpatias iam para aqueles que se haviam levantado, pregando o restabelecimento da disciplina e o retorno às normas constitucionais. [...] Já (estava) desiludido quanto às possibilidades de melhora do governo provisório, sempre fugidio e indeciso em suas atitudes... (1967, p. 81).

Claro que, Nelson, também, vê o oportunismo do presidente em algumas ocasiões, ao explorar principalmente o "medo ao comunismo" após a Intentona de 1935 e às vésperas do Estado Novo. Já instalada a ditadura, ele tece uma autocrítica de suas análises no período partindo, da falta de clareza nos rumos da política e das alianças de última hora comuns nesse campo:
Essa duplicidade nos repugnava: a falsa ideia de que pode haver sinceridade e pureza onde, por condições essenciais, tais virtudes estão naturalmente excluídas, domina o ingênuo julgamento das pessoas da classe média, entre as quais as dos militares destacam-se como típicas. O ideal de austeridade em que se embalam, sincero sentimento que preside a escala de valores a que obedecem, revela, apenas, desconhecimento das relações essenciais da vida em sociedade, em um regime como o nosso (1967, p. 143).

Apesar da autocrítica expressa, é essa austeridade e um alto grau de exigência moral que marca as reflexões de seu texto autobiográfico. A escrita de si está marcada pela procura de coerência, que ele projeta, na citação acima, ao campo da política. Teoricamente, sabe que isso é impossível "em um regime (capitalista? corrupto?) como o nosso". Maquiavel, afinal, já demonstrara como a política não pode ser feita pela sinceridade e pelas boas intenções, mas o pensador italiano, igualmente, ressaltava o valor da virtú. Parece-nos que Miguel Reale soube desfrutar melhor desse aspecto da ação política, buscando seguir a fortuna $a^{5}$

\section{0 enigma de Reale}

Quando eclodiu a Revolução de 1930, Miguel era um estudante de 20 anos cursando Direito na Faculdade de São Paulo. Vivia, ali, o clima de agitação pré-revolucionária, os debates sobre o programa político da Aliança Liberal e a vitória não comemorada do paulista Julio Prestes nas eleições presidenciais. Aquela juventude estudantil era contra os jogos políticos oligárquicos, apoiando o movimento revolucionário que impediu a posse do presidente eleito. Ele logo ressalta 
o significado ambíguo do regime instituído por Getúlio Vargas, já que

[...] gerou novos problemas de cunho social e econômico; inoculou o fermento das ideologias, do Fascismo ao Comunismo; rompeu com as antigas oligarquias estaduais, fazendo emergir o povo brasileiro e passando para o cenário amplo da Nação os problemas que eram antes previamente resolvidos nos quadros estreitos das fronteiras dos Estados[...]. Minha geração viveu intensamente esses contrastes... (1987, p. 58).

Tal avaliação indica a dificuldade de construir um juízo claro na época dos acontecimentos. Aponta, ainda, para o que irá se seguir na narrativa, pois a autobiografia de Miguel Reale dedica boas páginas acerca de sua militância na Ação Integralista Brasileira (AIB) durante os anos de 1930. Não é que se arrependa de ter participado do movimento, bom deixar claro, pois ele assume suas ações e escritos de juventude ${ }^{6}$. Contudo, essa opinião, expressa cinco décadas depois, parece preparar o leitor para o engajamento visceral que fará naquela associação.

Plínio Salgado, o famoso líder da AIB, era da mesma cidade de Miguel, São Bento de Sapucaí, em São Paulo. O encontro entre os dois ocorreu em outubro de 1932, havendo logo grande sintonia (REALE, 1987, p. 72). Graças a isso, o primeiro livro, do ainda estudante de direito, foi publicado, abordando as características do Estado Moderno. O ideal básico expresso era o do corporativismo, associado ao nacionalismo e à busca da ordem.

Miguel Reale chegou à direção do movimento integralista, ocupando o importante cargo de secretário nacional de doutrina. Após o chamado putsch contra Getúlio ${ }^{7}$ e a prisão dos líderes da AIB, o estudante resolveu fugir clandestino para a Itália, conseguindo retornar cerca de um ano depois. Foi, então, que se formou e tentou começar sua carreira de professor de direito mediante concurso público. Após alguns quiproquós, ele acabou tendo de recorrer ao presidente da República para tomar posse do cargo de docente.

O encontro ocorreu com bastante temor por parte de Reale, que não sabia qual seria a reação de Vargas. O diálogo transcrito nas Memórias é deveras interessante. Depois de fazer o relato do problema na audiência, "o presidente sorriu enigmaticamente e, após uma baforada de charuto", teria dito:

- Pode ficar descansado. Se o Conselho Federal de Educação reconhecer seu direito, este será respeitado. E comentou: Pelo visto, a Faculdade de Direito de São Paulo continua sendo a fortaleza do passado.

Entretendo conversa cordial, confidenciou-me que sempre tivera atração pelos estudos de filosofia [...]; arrematou suas considerações lembrando que chegara a alimentar o propósito de tornar-se professor de Filosofia do Direito, em Porto Alegre, mas convidado por Borges de Medeiros para ser deputado, sua vida tomara outros rumos.

- Se perdemos um filósofo do Direito, comentei prontamente, a Nação ganhou um grande estadista (REALE, 1987, p. 152).

$\mathrm{O}$ diálogo é cheio de ambiguidade. $\mathrm{O}$ presidente Vargas exime-se de intervir, mas seu comentário irônico deixa transparecer que ele apoia ao que fora requerido. Afinal, falava o líder maior da Revolução de 1930, feita em nome da mudança, do novo Brasil e da ruptura com o passado. Seria, assim, uma referência às oligarquias paulistas en- 
casteladas na Faculdade? Mas peso dado ao passado pode ser também uma referência à vida pessoal de Miguel Reale, que por causa de seu envolvimento com o integralismo fora impedido de assumir o cargo. Esse fato estaria sendo colocado acima da avaliação de sua competência.

Curiosamente, a conversa direciona-se para lembranças pessoais, para o passado de Vargas, e o clima parece ficar menos tenso. Uma identificação entre ambos é logo estabelecida, pois teriam o gosto pela filosofia do direito. Assim, o complemento feito pelo advogado é, igualmente, ambíguo, pois um grande estadista traz para a prática uma filosofia da governabilidade, tema central da filosofia do direito. Vargas, então, seria os dois, mesmo não tratando sistematicamente da reflexão acadêmica. $\mathrm{O}$ elogio realizado de maneira objetiva, em linguagem indireta, não envolve necessariamente o apoio pessoal ao regime varguista, mas deixa implícito o reconhecimento de sua habilidade com as palavras, os gestos, as atitudes e ideias.

O artifício de Reale deu certo e ele assumiu, não sem graves conflitos com os estudantes por causa do engajamento no integralismo, a cátedra de filosofia do direito. A contrapartida não tardou, pois dois anos mais tarde o presidente convidou-o para compor o Conselho Administrativo do Estado de São Paulo. Esse órgão era uma peça chave na organização do Estado Novo, responsável tanto por decisões legislativas quanto executivas. Getúlio teria dito que precisava de "sangue novo em São Paulo" e Miguel aceitou o convite de imediato (1987, p. 164).
Como se vê, o comportamento do professor é também ambíguo, semelhante ao de Getúlio. Enquanto integralista participara do golpe frustrado contra o presidente e depois contribui integralmente para seu regime. Ainda antes do fim do Estado Novo, estará novamente na oposição. Ele, também, parece se posicionar de acordo com as circunstâncias, mesmo que o texto das Memórias se esforce retoricamente para demonstrar a coerência da vida e da obra.

\section{Considerações finais}

As várias visões de Vargas acontecem porque Getúlio Vargas foi um político de muitas faces? Não necessariamente. Em que pese a dificuldade de interpretar esse personagem histórico e sua herança política (CAMARGO, 1999), pode-se considerar que as pessoas são cotidianamente plurais e no cenário social desenvolvem muitos papéis. As avaliações expressas pelas memórias dos intelectuais aqui tratados, homens hábeis na reflexão e nas palavras, refletem a própria identidade e os valores que propagam.

Isso não significa que sejam sem valor ou que inventem Vargas infinitos. A literatura testemunhal contém descrições de experiências vividas pelos atores, possuindo tanto veracidade quanto verossimilhança. Como indicou a perspectiva teórica de Ricouer, deve-se evitar os polos extremos na análise, rejeitando ruptura ocorrida entre os estudos da memória e a epistemologia do testemunho.

A primeira corrente provém dos herdeiros de Halbwachs, ressaltando o lado social da lembrança, sua (re)construção pelo 
presente, as estratégias de manipulação pelos grupos sociais e seu caráter representacional. Um bom exemplo dela está na obra dirigida por Pierre Nora (1984-1987). Já, a vertente voltada para o estudo do testemunho, tem sido desenvolvida principalmente no mundo anglo-saxão. Seus fundamentos envolvem mais a psicologia, a pragmática dos discursos e a filosofia analítica, encontrando-se uma boa síntese no artigo de Jonanthan Adler (2010). Ora, os aspectos individuais e sociais estão longe de serem opostos, sendo evidente que ambos constituem-se com base nos vínculos estabelecidos pelas lembranças . Com as fontes históricas autobiográficas, também, é assim.

\section{Abstract}

Autobiografical literature is a rich source to historical knowledge, although the traps in this type of text. The article approaches three books of memories, published by militant intellectuals: Alceu Amoroso Lima, a catholic leader, the Communist Nelson Werneck Sodré and a liberal of right Miguel Reale. The axe of this inquiry are the interpretations that they had made of the Revolução de Trinta and of President Getúlio Vargas.

Keywords: Intellectuals. Autobiography. Revolução de Trinta. Getúlio Vargas.

\section{Resumen}

La literatura autobiográfica es una rica fuente para el conocimiento del pasado, a pesar de las trampas que presenta. Ese artículo aborda tres obras de este género, publicadas por intelectuales militan- tes: el católico Alceu Amoros Lima, el comunista Nelson Werneck Sodré y el liberal de derecha Miguel Reale. El eje de la investigación es la interpretación que hicieron de la Revolução de Trinta y del Presidente Vargas.

Palabras-clave: Intelectuales. Autobiografía. Revolução de Trinta. Getúlio Vargas.

\section{Notas}

1 Alceu Amoroso Lima teve encontros, na década de cinquenta, com Claudel e nesse opúsculo demonstra uma profunda admiração pelo teatrólogo francês (LIMA, 1959).

2 Esse conceito tem sido trabalhado na historiografia de maneira ampla, lançado pelo grupo da CEHILA no início da década de 1970 do século passado. Ele indica a busca da reconquista, da retomada da influência cultural e política do catolicismo na sociedade latino-americana, inspirada pelo neo-tomismo e por uma visão idealizada da cristandade medieval.

3 O relato de José Oscar Beozzo sobre essa negociação beira o dramático: "As gestões de D. Leme junto a Washignton Luis foram infrutíferas e só quando as fortalezas decidem bombardear o Palácio da Guanabara, já cercado por tropas insurretas, consegue o Cardeal um acordo 'in extremis' com os chefes militares, visando salvar apenas a vida do presidente e de seus auxiliares. Este sai do Palácio, acompanhado pelo Cardeal sob o apupo e as ameaças da multidão..." (1995, p. 289).

4 Curiosamente, a Historia das ideias socialistas no Brasil de Vamireh Chacon (1981) e o estudo de Edgard Carone (1986) acerca d'O marxismo no Brasil deram pouquíssimo destaque às concepções de Sodré. Marcos Silva (2008), mais recentemente, tem dado realce à importância da visão de Sodré sobre o Brasil e demonstra sua relevância como intelectual militante, retirando-lhe a pecha de ser um mero stalinista.

5 Referimo-nos às duas forças básicas que regem a história na concepção de Maquiavel (cf. SKINNER, 1988).

6 Concordamos com Rogério L. Victor quando ressalta a importância da Ação Integralista como o primeiro movimento político de massas e de caráter nacional. Posteriormente, o envolvimento 
de muitos líderes passou a ser comentado com certa vergonha e houve um processo de apagamento na história política brasileira (VICTOR, 2005).

7 Trata-se de uma tentativa de invasão do Palácio da Guanabara, onde vivia Vargas, que foi rapidamente desbaratada pelos militares. Isso motivou a prisão e o exílio de Plínio Salgado, bem como da liderança da Ação Integralista Brasileira.

\section{Bibliografia}

ADLER, Jonathan. Epistemological problems of testimony. In: ZALTA, Edward N. (Ed.). The Stanford Encyclopedia of Philosophy, 2010. Disponível em:<http: //plato.stanford.edu/testimony-episprob/> . Acesso em: 25 ago. 2012.

BEOZZO, José Oscar. A igreja entre a Revolução de 1930, o Estado Novo e a redemocratização. In: FAUSTO, B. (Ed.). O Brasil Republicano - v. 4. 3. ed. Rio de Janeiro: Bertrand Brasil, 1995, p. 272-380.

BOURDIEU, Pierre. Campo de poder, campo intelectual. Buenos Aires: Editorial Montesinos, 2004.

CARONE, Edgard. O marxismo no Brasil. Rio de Janeiro: Contraponto, 1986.

CHACON, Vamireh. História das ideias socialistas no Brasil. Rio de Janeiro: Civilização Brasileira, 1981.

CLAUDEL, Paul. Mémoires Improvisés. Paris: Gallimard, 1954.

CAMARGO, Aspásia. Carisma e personalidade política: Vargas da conciliação ao maquiavelismo. In: D'ARAÚJO, Maria C. (Org.). As instituições brasileiras da Era Vargas. Rio de Janeiro: Editora da FGV, 1999, p. 13-35.

DIAS, Romualdo. Imagens da ordem. São Paulo: Editora da UNESP, 1996.

DUBY, Georges. A história continua. Rio de Janeiro: Jorge Zahar Editor, 1990.
DUBY, Georges. Guilherme Marechal - o melhor cavaleiro do mundo. São Paulo: Companhia das Letras, 1995.

GOMES, Angela de Castro (Org.). Escrita de si, escrita da história. Rio de Janeiro: FGV Editora, 2004.

GRAMSCI, Antonio. Os intelectuais e a organização da cultura. São Paulo: Círculo do Livro, $\mathrm{s} / \mathrm{d}$.

LE GOFF, Jacques. Os intelectuais na Idade Média. São Paulo: Brasiliense, 1988.

LIMA, Alceu. Memórias improvisadas. Petrópolis, RJ: Editora Vozes, 1973.

MICELI, Sérgio. Intelectuais e classe dirigente no Brasil. São Paulo: Difel, 1979.

NORA, Pierre. Lieux de Mémoire. v. 3. Paris: Gallimard, 1984-1987.

PECAULT, Daniel. Os intelectuais e a politica no Brasil. São Paulo: Ática, 1990.

REALE, Miguel. Memórias - destinos cruzados. São Paulo: Saraiva, 1986.

RICOEUR, Paul. La mémoire, l'histoire, l'oubli. Paris: Seuil, 2000.

SILVA, Marcos (Ed.). Dicionário crítico Nelson Werneck Sodré. Rio de Janeiro: Editora UFRJ, 2008.

SIRINELLI, Jean-François. Os intelectuais. In: REMOND, R. (Org.). Por uma história política. Rio de Janeiro: Editora FGV, 1996, p. 231-269.

SKINNER, Quentin. Maquiavel. São Paulo: Brasiliense, 1988.

SODRÉ, Nelson Werneck. Memórias de um soldado. Rio de Janeiro: Civilização Brasileira, 1967.

WINOCK, Michel. O século dos intelectuais. Rio de Janeiro: Bertrand Brasil, 2000.

VICTOR, Rogério Lustosa. O integralismo nas águas do Lete. Goiânia: Editora da UCG, 2005. 